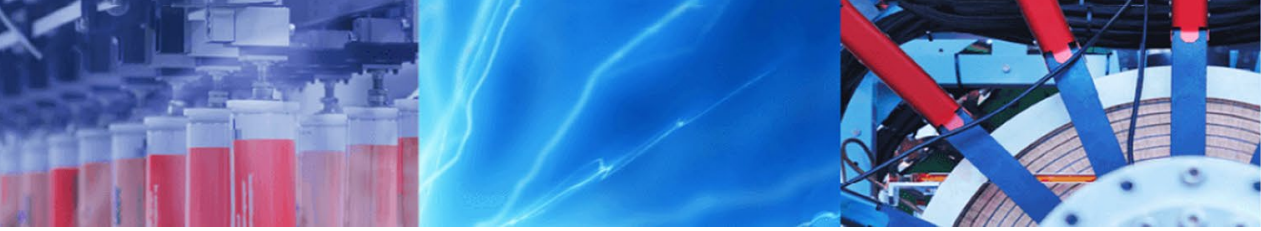

Research Article

\title{
Enzymatic synthesis of cosmetic grade wax ester in solvent free system: optimization, kinetic and thermodynamic studies
}

\author{
Kajal S. Jaiswal ${ }^{1}$ - Virendra K. Rathod ${ }^{1}$
}

(c) Springer Nature Switzerland AG 2019

\begin{abstract}
The enzymatic synthesis of cetyl caprate, a cosmetic grade ester was studied by esterification of cetyl alcohol and capric acid using Fermase CALB $^{\mathrm{TM}} 10000$ under solvent free condition. The process parameters namely, temperature, enzyme loading, molar ratio, agitation speed have been investigated and optimized to attain maximum yield of cetyl caprate. The maximum yield of $91.9 \%$ was obtained in 80 min under optimized conditions of $50{ }^{\circ} \mathrm{C}$ temperature, $3 \%$ enzyme loading, capric acid:cetyl alcohol ratio of 1:3, and $200 \mathrm{rpm}$ stirring speed. The enzyme operational stability study reveals that enzyme can retain its original activity for the synthesis of cetyl caprate and could be reused up to five to six times without any notable loss of catalytic activity. The kinetics of the reaction was derived by employing non-linear regression consideration, and the experimental results and kinetic evaluation showed that reaction obeys ping-pong bi-bi model. The kinetic parameters, $V_{\max }=21.886 \mathrm{M} / \mathrm{min} / \mathrm{g}$ catalyst, $K_{A}=1.194 \times 10^{-2} \mathrm{M}, K_{B}=8.4512 \mathrm{M}, K_{i A}=2.02 \times 10^{-2} \mathrm{M}$, $K_{i B}=3.55 \times 10^{-4} \mathrm{M}$ and $S S E=4.31 \times 10^{-5}$ measured from initial rate data were used to replicate experimental results with good agreement. The thermodynamic parameters, i.e., change in enthalpy, Gibb's free energy, change in entropy was evaluated at different operating temperatures. Thus, current research work strikes a significant imprint in the cosmetic industry by synthesizing green and natural product using biocatalysis under solvent free condition.
\end{abstract}

Keywords Cetyl caprate $\cdot$ Cosmetic emollient $\cdot$ Esterification $\cdot$ Lipase $\cdot$ Kinetic study

\section{Introduction}

Long chain esters with a chain length of 12 carbons or more with higher boiling points are specifications of wax esters. They hold excellent specific characteristics such as emulsifying as well as stabilizing system. They are biocompatible and biodegradable having non-toxic nature and the widespread application in various important cosmetic formulations as emollients, moisturizers, and conditioning agents, are owed to its properties such as good fat solubility, and wetting property at interfaces and smearing the wax over the skin to give a moisturizing, soothing property and not sticky or greasy feeling [1]. They can also be used as additives auxiliaries, antifoaming agents, lubricants, plasticizers, polishers, etc. [2, 3]. Petroleum-based emollients are the environment-friendly alternative of the esters derived from fatty acids. Consumer's requirement of the green and natural product along with the standards of eco-friendly mindset is satisfied by using biocatalysis for the synthesis of various commercially essential esters. Wax esters synthesized via enzymatic pathway are reviewed similar to natural wax esters and therefore can be used safely and risk-free in cosmetic and food industries.

The most profoundly used class of biocatalyst for biotechnological reaction for the synthesis of organic chemicals is the lipase enzyme. They have achieved immense significance in biocatalysis field as they have the potential to catalyze various organic synthesis in non-aqueous media. Enzyme lipases are forthwith attracting a substantial deal of interest to researchers and industrialists as they

$\triangle$ Virendra K. Rathod, vk.rathod@ictmumbai.edu.in | 'Department of Chemical Engineering, Institute of Chemical Technology, Matunga (E), Mumbai 400019, India.

SN Applied Sciences (2019) 1:949 | https://doi.org/10.1007/s42452-019-0955-9 
own extensive substrate stereoselectivity, chemoselectivity, and regioselectivity. The broad adaptability of lipase catalysis in the synthesis of a cosmetic group of esters is required to be explored and investigated. Naturally available wax esters through natural secretions of plants and animal are typically high-priced as the sources are finite [4]. Bio-chemical catalyzed routes have distinctive advantages over chemical catalyzed reactions, and remarkable considerations are driven towards enzyme catalysis correlative to the customary chemical catalyzed approach, particularly in the synthesis of flavor esters and cosmetic esters [5].

Wax esters materials are held as commodity items in cosmetic companies, and recently synthetic wax esters synthesized via enzymatic pathway have acquired enormous engrossment among cosmetic researchers with respect to their use in cosmetic industries; also biocatalysis imparts standards and grades obligatory for cosmetic use $[6,7]$. The global market for cosmetics is exceeding as numerous new cosmetic products introduced to the market continues to spread out extensively. Natural wax esters are versatile but burdened with accessibility and convenience. The organic processing industries of waxes have different purposes such as plasticizing agents, emollients, surfactants, solvents, etc. and specific applications can be met by cetyl caprate which is an important commercially available intermediate ester. Enzymatic synthesis has been reported from shorts-chain acids and alcohols used as flavor and fragrances compounds in foods to long chain fatty acid wax esters used in large numbers of cosmetic formulations as emollients and conditioning agents $[5,8]$. Cosmetic products involve persistent use of synthetic wax esters, and they can be synthesized by direct esterification or transesterification. Literature reports about the enzymatic esterification of capric acid esters are confined. Synthesis of enzyme catalyzed xylitol caprate using xylitol and capric acid reached a conversion upto $74.05 \%$ in $29 \mathrm{~h}$ reaction time in solvent free system [9]. The lipase catalyzed synthesis of cetyl oleate reached equilibrium in $8 \mathrm{~h}$ to give $98 \%$ conversion at $40^{\circ} \mathrm{C}$, also retained $46 \%$ conversion rate after reuse for 6-7 cycles [3]. The enzymatic esterification of cetyl alcohol in the presence of candida lipase has been reported to yield $98 \%$ conversion within $8 \mathrm{~h}$ [10]. The lipase catalysed the synthesis of cetyl octanoate using cetyl alcohol as acyl acceptor gave a conversion of approximately $94 \%$ in the presence of $n$-hexane within $5 \mathrm{~h}$ reaction time [11].

For many decades, cosmetic researchers have reported the enzyme catalyzed the synthesis of fatty acid ester in the presence of organic solvent [12-16]. Major attention is urged on green biocatalysis synthesis pathway instead of toxic chemical solvents, and there is a dearth of literature on enzyme catalysed synthesis of fatty acid esters, especially with a high cosmetic grade in solvent free system. Recently extensive efforts are directed by researchers and industrialist to synthesize esters in solvent free system. In view of this, considerable work has been dedicated towards the synthesis in SFS, as it simplifies the downstream processing, operates at mild reaction condition, furnishes high purity compounds by evading high-budget separation techniques [10].

Hence, it was thought worthwhile to study the esterification reaction using lipase enzyme in solvent free system. To date, there has been no report in past on the synthesis of cetyl caprate with kinetic study and thermodynamic study to the best of our knowledge. In the current protocol, we herein account the synthesis of cosmetic grade ester, cetyl caprate using cetyl alcohol as acyl donor and capric acid catalyzed by a commercial immobilised Candida antarctica lipase (Fermase CALB $\left.{ }^{\mathrm{TM}} 10000\right)$, employing optimization, mechanism, thermodynamic study, reaction condition for the kinetically controlled synthesis through immobilised lipase mediated esterification.

\section{Materials and methods}

\subsection{Materials}

Analytical grade cetyl caprate (99.5\%) was procured from Thomas Baker (Chemicals) Pvt. Ltd., Mumbai. Capric acid (98\%) utilized in the reaction study was supplied from Loba Chemie Pvt. Ltd., Mumbai. A commercial Candida antarctica lipase $B$, Fermase CALB ${ }^{\mathrm{TM}} 10000$ immobilized on polyacrylate beads was obtained from Fermenta Biotech Ltd., Mumbai. This enzyme has been selected as the activity of Novozym 435 and Fermase CALB ${ }^{\text {TM }} 10000$ are almost similar, also Fermase is cheaper as compared to Novozym 435. Molecular sieves $\left(4^{\circ} \mathrm{A}\right)$ were bought from $\mathrm{M} / \mathrm{s}$ Merck Ltd., Mumbai. The analytical grade ethanol, potassium hydroxide, Phenolphthalein, sodium carbonate used for analysis were purchased from Thomas Baker (Chemicals) Pvt. Ltd., Mumbai.

\subsection{Method}

\subsubsection{Esterification reaction}

The customary esterification of cetyl caprate was performed in a $50 \mathrm{ml}$ flat bottom glass reactor furnished with four baffles and three bladed turbine impeller for agitation purpose. The glass setup was clamped on a thermostatic water bath with a temperature control program. The synthesis of cetyl caprate involves the addition of cetyl alcohol and capric acid in a fixed molar ratio within the 
glass reactor to round up the volume of reaction up to $15 \mathrm{~mL}$ without making use of any solvent. The reaction mass was stirred for 5 min to form a homogenous phase, followed by the addition of a given amount of biocatalyst and molecular sieves to start the process. The reactor containing the reaction mixture was maintained at a specified temperature and agitation speed. The reaction progress was checked periodically and analyzed by standard acid value method to determine percent conversion [17]. After the first batch, the enzyme reusability was also taken into account. The enzymes were separated from the reaction mixture through filtration using Whatman filter paper, and the enzymes were rinsed several times using acetone. The washed enzymes were stored in a desiccator for a period of $24 \mathrm{~h}$ until used for the next cycle. where $\mathrm{V}_{0}$ is the volume of blank titrated against $\mathrm{NaOH}, \mathrm{V}$ is the volume of the samples titrated against the alkali, $M$ represents molarity of the $\mathrm{NaOH}$ from standardization, $\mathrm{A}$ represents weight of the enzyme, $T$ is the time of reaction in minutes.

\subsubsection{Titrimetric analysis}

The synthesized product cetyl caprate was signified in terms of percent (\%) conversion. The percentage conversion (\%) of cetyl caprate was determined in terms of acid value by calculating the residual capric acid in the reaction mass by titration against $0.01 \mathrm{~N} \mathrm{KOH}$ using phenolphthalein indicator and by adding ethanol to stop the reaction. The samples for analysis were titrated in triplicate for accuracy. Percent conversion was evaluated as follow:

$\frac{\text { Volume of } \mathrm{KOH} \text { utilised (without enzyme) - Volume of } \mathrm{KOH} \text { utilised (with enzyme) }}{\text { Volume of } \mathrm{KOH} \text { utilised (without enzyme) }} \times 100$

\subsubsection{Purification}

The residual reaction mass was filtered through Whatman filter paper to separate the lipase enzymes. The remaining residue contained cetyl caprate, unreacted capric acid, and unreacted cetyl alcohol. The unreacted capric acid was offset and neutralized using a base such as a solution of saturated sodium hydroxide, and cetyl alcohol that was unreacted was eliminated by ethanol extraction [11]. The purification process neutralizes unreacted acid so that the product is free from acid for cosmetic use.

\subsubsection{Lipase enzyme activity}

The lipase enzyme activity was analyzed from the procedure outlined and reported in the literature [18]. The stock solution comprised of $85.95 \mathrm{~mL} \mathrm{n}$-heptane containing $2.7 \mathrm{~mL}$ butanol $(0.33 \mathrm{M})$ and $1.35 \mathrm{~mL}$ butyric acid $(0.16 \mathrm{M})$. Based on this methodology, the weighed quantity of enzyme lipase was added to a conical flask that already contained $3 \mathrm{~mL}$ of stock solution. The conical flask was mounted on the incubated shaker and kept at $40^{\circ} \mathrm{C}$, $50^{\circ} \mathrm{C}$ and $60^{\circ} \mathrm{C}$ with stirring speed of $150 \mathrm{rpm}$ for $60 \mathrm{~min}$. After $1 \mathrm{~h}$, the reaction was quenched with $1 \mathrm{~mL}$ of ethanol and after adding phenolphthalein indicator, immediately titrated against $0.02 \mathrm{M}$ alcoholic potassium hydroxide solution. The esterification activity was followed as,

Enzyme activity $(E a)=\frac{(V o-V) \times M \times 100}{A \times T}$

\subsubsection{FT-IR analysis}

Fourier transfer infrared spectroscopy (FT-IR) (Shimadzu, Miracle 10, and IR Affinity-1S) was approximated for identification of functional group present in the product. The IR spectra of analytes were evaluated by using transmission mode. The FT-IR spectra were scanned under the range of around $500-4000 \mathrm{~cm}^{-1}$. The FT-IR spectra show a band at about $1700-1600 \mathrm{~cm}^{-1}$ which is assigned at $1720.12 \mathrm{~cm}^{-1}$ that can be accredited to stretching of carbonyl group $(-\mathrm{C}=\mathrm{O})$ that supports the formation of product ester.

\subsubsection{Statistical analysis}

Statistical analysis is a useful mechanistic tool to explicate and summaries the experimental results generated by performing various experiments, and Microsoft excel was used to analyze the results. The experimental study was carried out in triplicate for accuracy and precision, and the reports generated are illustrated as mean $\pm S D$ in the present work. For a statistically significant outcome, $P$ value less than 0.05 are considerable.

\section{Results and discussion}

In order to gain a better understanding of reaction parameters governing the enzyme catalyzed synthesis of cetyl caprate, the optimization studies for esterification of cetyl alcohol and capric acid were conducted which includes influence of various operational parameters such as effect 

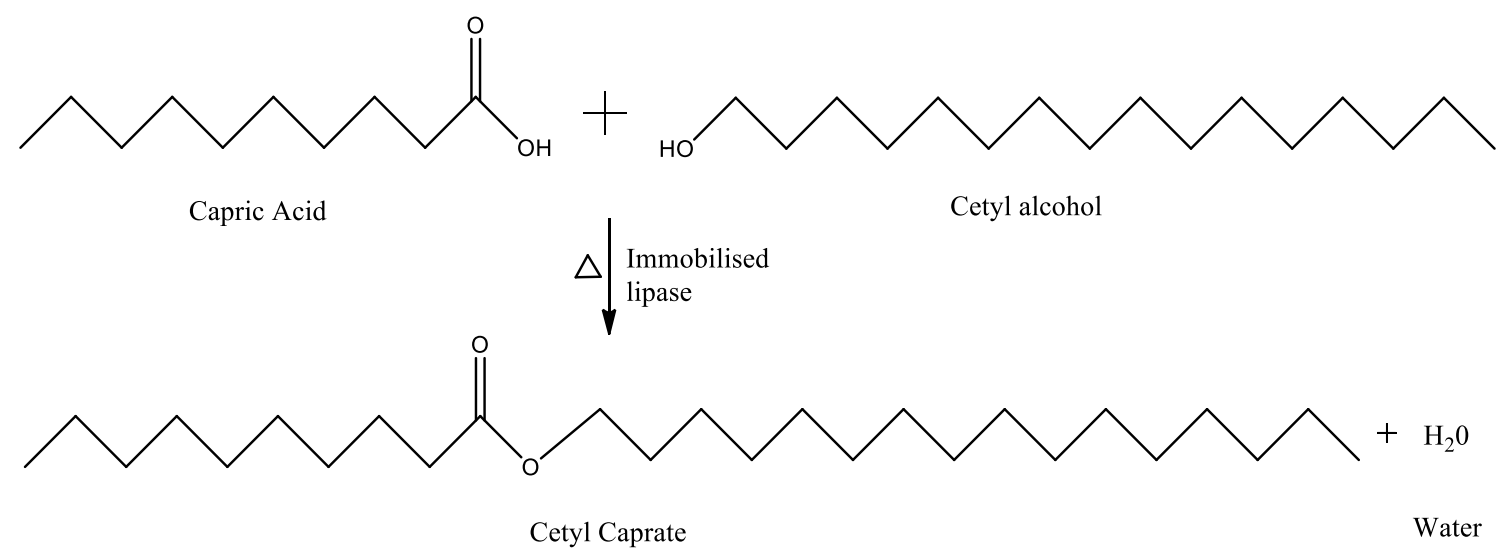

Scheme 1 Cetyl caprate synthesis

of molar ratio, effect of enzyme loading, effect of temperature, effect of agitation speed and reusability studies (Scheme 1). The details of each operating parameters are discussed below.

\subsection{Effect of temperature}

The influence of temperature on cetyl caprate synthesis by immobilized lipase was examined accurately by varying it from 40 to $55^{\circ} \mathrm{C}\left(40^{\circ} \mathrm{C}, 45^{\circ} \mathrm{C}, 50^{\circ} \mathrm{C}, 55^{\circ} \mathrm{C}\right)$. The temperature of the reaction is considered to be a significant variable affecting the conversion rates and possible denaturation and deactivation of catalytic activity of enzyme lipase. Previous work on enzyme catalyzed synthesis reported that optimum reaction temperature is required to drive the reaction successfully in the forward direction and obtain better conversion yields. The use of biocatalyst needs mild temperature set up that can be easily maintained. The temperature study in biocatalysis casts light on the molecular collision interaction as well as substrate solubility. A closer examination of the effect of temperature in Fig. 1a depicts that percent conversion increased from 61.35 to $91.98 \%$ as the temperature increased from 40 to $55^{\circ} \mathrm{C}$. The conversion obtained at $40^{\circ} \mathrm{C}$ and $45^{\circ} \mathrm{C}$ was $61.35 \%$ and $77.22 \%$ respectively. At lower temperature, the enzyme and substrate show poor molecular collision interaction that eventually leads to poor conversion. Due to this poor interaction, all the enzyme particles are not used up by the reactive species. At higher temperature at $50{ }^{\circ} \mathrm{C}$ the enzyme and substrate possess strong molecular interaction, and at $50^{\circ} \mathrm{C}$ the esterification reaction was found to be highly effective with $91.98 \%$ yield in $80 \mathrm{~min}$ reaction time. The higher temperature brings out a higher conversion, elevating the molecular interaction between enzyme catalyst and the substrate by abating the viscosity of the reaction mixture. The results obtained at $55^{\circ} \mathrm{C}$ was almost the same as obtained at $50^{\circ} \mathrm{C}$ and showed a
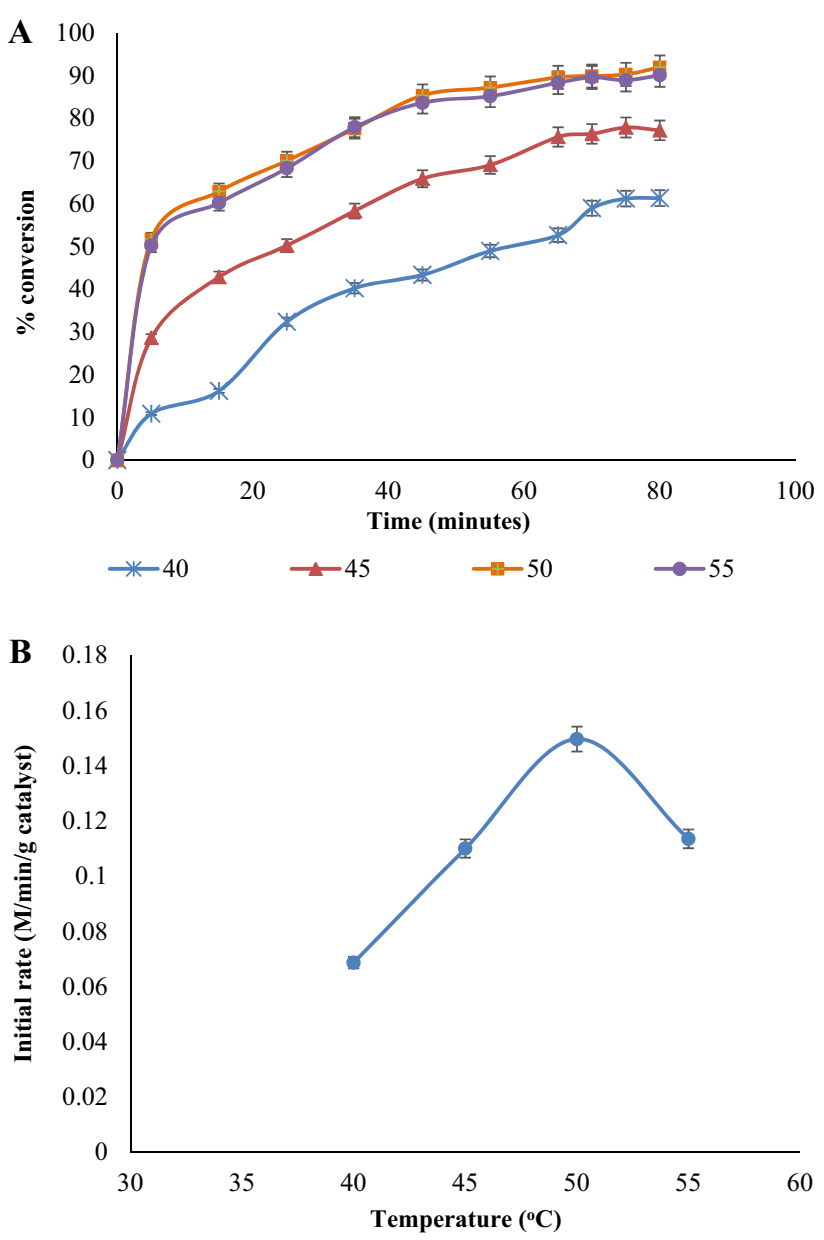

Fig. 1 Effect of temperature on conversion (a) and initial rate versus temperature (b). Reaction condition: time-80 min, enzyme dose-3\% w/w, capric acid:cetyl alcohol ratio-1:3, speed of agitation-200 rpm

marginal improvement in the conversion. Therefore, the systematic optimization of temperature indicates that 
the esterification reaction proceeded efficiently at $50{ }^{\circ} \mathrm{C}$ and followed for further experimental studies. Figure $1 \mathrm{~b}$ reveals that the initial rate of reaction increased from $0.06 \mathrm{M} / \mathrm{min} / \mathrm{g}$ catalyst to $0.15 \mathrm{M} / \mathrm{min} / \mathrm{g}$ catalyst as the temperature increases from 40 to $50^{\circ} \mathrm{C}$ however the initial rate of reaction reduces at $55^{\circ} \mathrm{C}$.

For esterification reaction catalyzed by Fermase CAL B, the activation energy was calculated using the rate constant at different temperatures altering from 40 to $55^{\circ} \mathrm{C}$. Activation energy is the lowest energy entails to modify a typical steady species to an unstable species and the energy requisite for configuration of transition state from reactants. It is the deviation among the reactant state and the product state. For the existing scheme, the Arrhenius plot was formulated on the basis of data of initial rate versus reciprocal of temperature in order to figure out the activation energy of esterification of cetyl caprate [19]. The fundamental Arrhenius equation is as follow;

$\ln \mathrm{K}=-\mathrm{E}_{\mathrm{a}} / \mathrm{RT}+\ln \mathrm{A}$

Here $A$ represents the frequency factor; $K$ represents the reaction rate constant; $E_{a}$ denotes as the activation energy $(\mathrm{kJ} / \mathrm{mol})$, and $\mathrm{T}$ is the temperature.

As seen from Fig. 2, the rate statistics at various temperatures extending from 40 to $55^{\circ} \mathrm{C}$ have been studied by using 3\% enzyme dose, the molar ratio (acid:alcohol) 1:3 and stirring speed of $200 \mathrm{rpm}$. The activation energy for cetyl caprate synthesis catalyzed by immobilized lipase was found to be $11.0 \mathrm{kcal} / \mathrm{mol}(45.99 \mathrm{~kJ} / \mathrm{mol})$, that in particular fall in between the scale of enzyme catalyzed reactions, proportionate to that reported in the literature $[12,20]$. The activation energy value for esterification of oleic acid and decanol using Novozym 435 as a catalyst in hexane medium is reported as $16.24 \mathrm{kcal} / \mathrm{mol}$ [21]. The

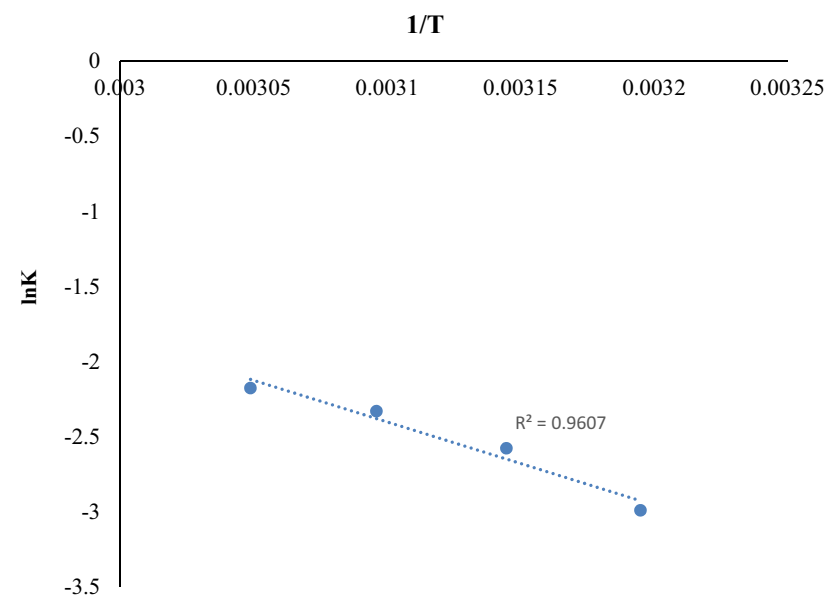

Fig. 2 Arrhenius plot for esterification of cetyl caprate for obtaining the activation energy minimal activation energy estimate indicates superior catalytic proficiency of immobilized lipase [22].

\subsection{Effect of enzyme loading}

The enzyme has an intriguing potential of prosecuting a distinctly specific and efficient catalysis reaction. Enzyme loading is a critical parameter in view of the outcome of economic viability and practicability. The effect of enzyme amount on synthesis of cosmetic ester was tested from 2 to $3.5 \%(2 \%, 2.5 \%, 2.8 \%, 3.0 \%$, and $3.5 \%)$ under optimised condition. It is illustrated in Fig. 3a that the overall conversion increased from 63.75 to $91.91 \%$ with increasing catalyst loading from 2 to $3 \%$ and maximum conversion of $91.91 \%$ has been achieved with $3 \%$ enzyme loading. The amount of enzyme loading beyond $3 \% \mathrm{w} / \mathrm{w}$ did not show a significant increase in the percent conversion of cetyl caprate as the excess enzyme does not contribute
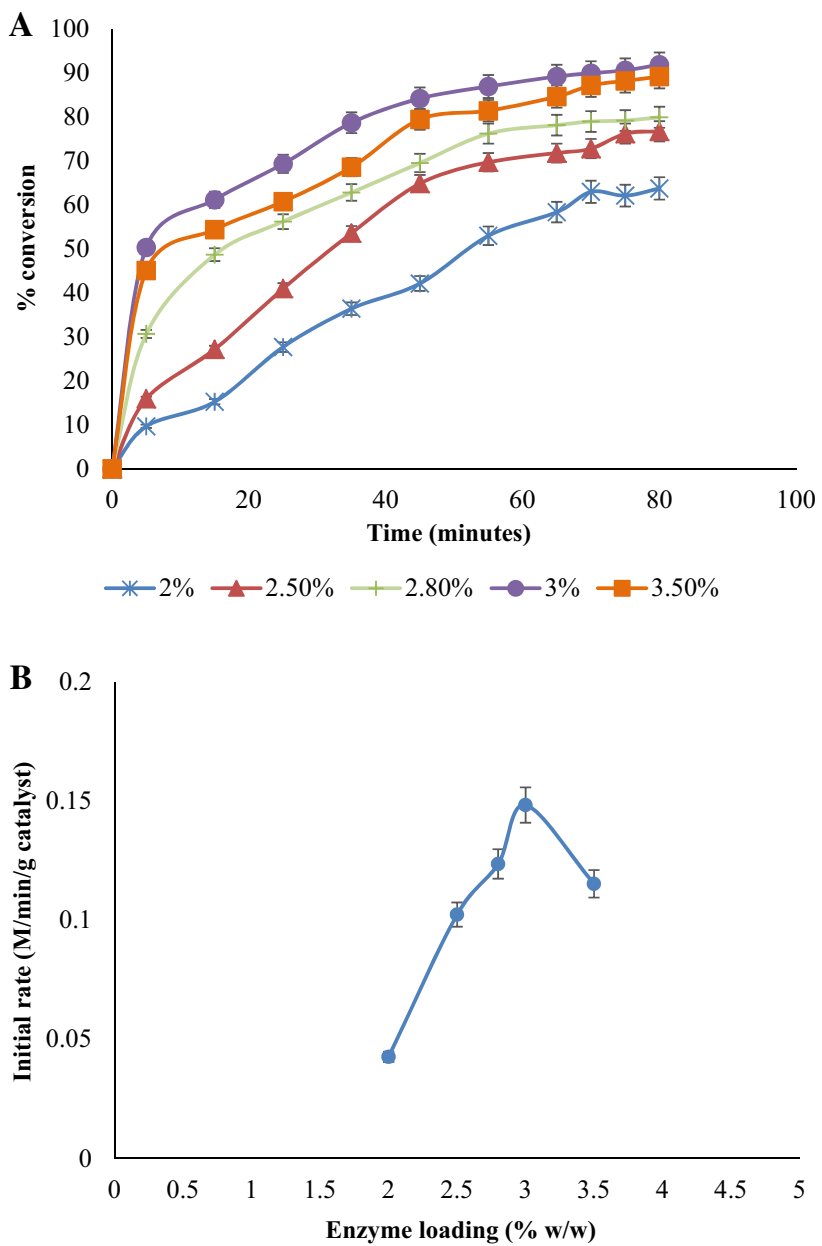

Fig. 3 Effect of enzyme loading on conversion (a) and initial rate versus enzyme loading (b). Reaction condition: time-80 min, temperature- $55^{\circ} \mathrm{C}$, capric acid:cetyl alcohol ratio-1:3, speed of agitation-200 rpm 
to enhance conversion due to unavailability of substrate. Also, excessive use of enzyme beyond optimum quantity at $3.5 \%$ may lead to agglomeration of immobilised enzyme lipase in absence of any solvent and possibly hamper the mixing and mass transfer limitation [11, 23]. Figure $3 \mathrm{~b}$ brings to view that the initial rate of reaction $(0.15 \mathrm{M} / \mathrm{min} / \mathrm{g}$ catalyst) is predominant with use of $3 \%$ $(\mathrm{w} / \mathrm{w})$ of enzyme dose while the initial rate of reaction drops beyond 3\% (w/w) enzyme dose. A similar type of correlation for conversion rate in terms of the amount of enzyme catalyst used was witnessed for the synthesis of ethyl-3-phenylpropanoate [24]. The behavior of excess optimum amount of immobilized lipase for higher conversion has also been reported [25]. Thus taking into account the economic feasibility, the excess use of biocatalyst was confined and concluded that $3 \% \mathrm{w} / \mathrm{w}$ as an optimum enzyme loading.

\subsection{Effect of molar ratio}

The impact of varying the molar ratio of capric acid: cetyl alcohol catalyzed by immobilized lipase was studied in the range between $1: 1$ to $1: 4$, i.e. $(1: 1,1: 2,1: 3.1: 4)$ and the reaction volume was sustained at $15 \mathrm{~cm}^{3}$. In the ongoing research, the end result of the influence of the molar ratio on the conversion rate has been laid out in Fig. 4a. The results delineate that a maximum percentage conversion of $91.3 \%$ and a determined rate of reaction were performed with 1:3 molar ratio of capric acid: cetyl alcohol in $80 \mathrm{~min}$. The percentage conversion increased together with an improvement in a molar ratio of substrate to a definite quantity. The percentage conversion was increased from 63.9 to $91.3 \%$ by increasing the capric acid:cetyl alcohol concentration from 1:1 to $1: 3$ and a maximized conversion was achieved at 1:3. With increasing the alcohol concentration, the availability of substrate towards the catalytic site of enzyme increases and assists to ease the esterification for higher conversion [26, 27]. The initial rate depicted in Fig. $4 \mathrm{~b}$ reveals that initial rate arrives at a maximum value of $0.15 \mathrm{M} / \mathrm{min} / \mathrm{g}$ catalyst from $0.05 \mathrm{M} /$ $\mathrm{min} / \mathrm{g}$ catalyst and over again begin to drop that can be substantiated to inhibition caused by acid with extreme concentration. The gradual decrease in conversion beyond 1:3 could be imputed to some kind of steric interference or specificity of immobilized lipase towards the substrate [14, 28]. The lower conversion rate at higher molar ratio attributed to consequences of cetyl alcohol over the enzyme activity $[29,30]$. Since the reaction is carried out in solvent free system, substrate polarity is believed to be the most crucial factor in balancing enzyme stabilization [31]. Cetyl alcohol comprises a hydrophobic tail with a polar head. As the enzymes are hydrophobic, the hydrophobic core of the enzyme preferentially may interact with the
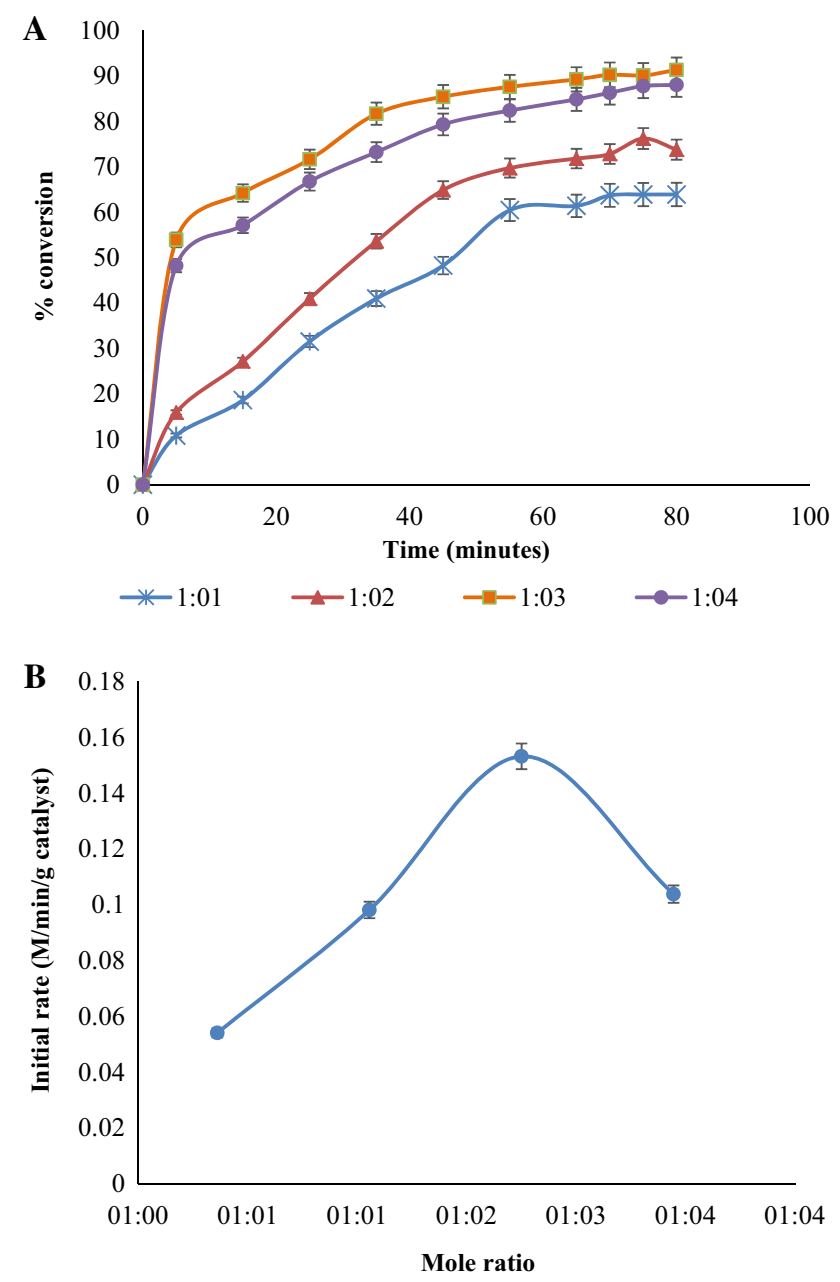

Fig. 4 Effect of molar ratio of capric acid and cetyl alcohol on conversion (a) and initial rate versus molar ratio (b). Reaction condition: time- $80 \mathrm{~min}$, temperature $-55^{\circ} \mathrm{C}$, enzyme dose- $3 \% \mathrm{w} / \mathrm{w}$, speed of agitation-200 rpm

hydrophobic tail of alcohol by increasing the residence duration of cetyl alcohol. The immobilization of enzyme was carried on polyacrylate beads possessing hydrophilic nature and possibly will entrap the water molecule deep within the immobilized support. The concentration of water and its residence duration on the microenvironment of the active enzyme surface is greater than that of the substrate. The hydrophobic/hydrophilic interaction breakdown can attribute to change in the protein structure of lipase. The higher concentration of alcohol at 1:4, i.e., beyond optimum value might slow down the reaction rate due to a steady distribution rate of cetyl alcohol on the active catalytic surface. Thus, the definite redundant nucleophilic concentration of $1: 3$ has been optimized and recruited in the given reaction. 


\subsection{Effect of agitation speed}

In the ongoing esterification reaction, the reaction mixture comprised of liquid phase containing reactants and solid phase of immobilized enzyme lipase and the external mass transfer resistance is effectively experienced while using immobilized lipase system. To evaluate the effect of external mass transfer limitation on esterification reaction between cetyl alcohol and capric acid catalyzed by immobilised lipase enzyme, the reactions were performed with different agitation speed [32]. The effect of agitation on the reaction medium was examined by ranging speed from 100 to $250 \mathrm{rpm}$. The Fig. 5a depicts the extent of esterification and the conversion increases with increase in the stirring speed from 100 to $200 \mathrm{rpm}$. The percent conversion obtained with a further lower stirring
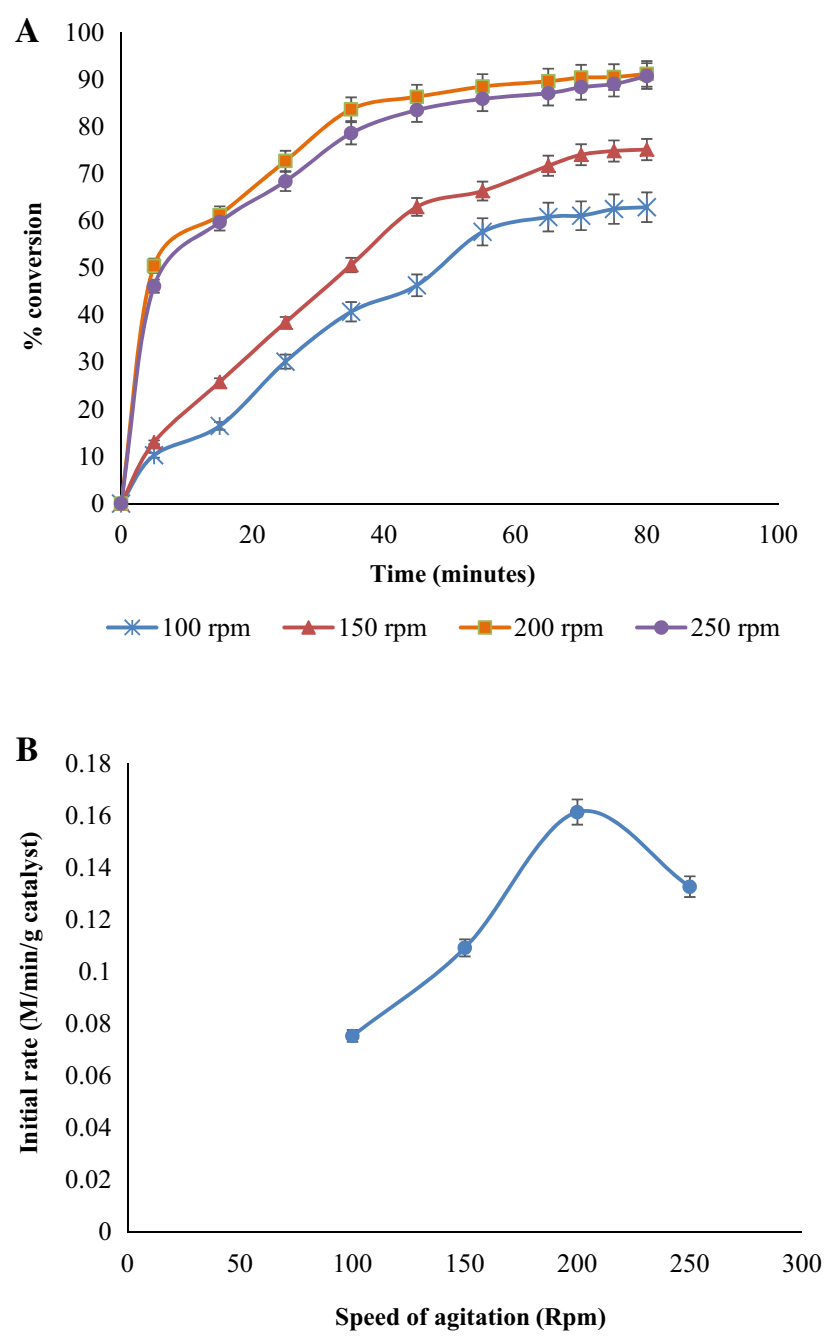

Fig. 5 Effect of agitation speed on conversion (a) and initial rate versus speed of agitation (b). Reaction condition: time-80 min, temperature- $55{ }^{\circ} \mathrm{C}$, enzyme dose- $3 \% \mathrm{w} / \mathrm{w}$, capric acid:cetyl alcohol ratio-1:3 speed of $100 \mathrm{rpm}$ and $150 \mathrm{rpm}$ was $62.91 \%$ and $75.15 \%$ respectively and at $200 \mathrm{rpm}$ stirring speed a maximum conversion of $91.19 \%$ was achieved. The agitation speed of $200 \mathrm{rpm}$ intermix the reactants by an increment in collision amongst the particles and the overall reaction rate intensifies in the relatively lesser duration of time, due to reduction in the external mass transfer resistance. As noticed in Fig. $5 b$, the initial rate of reaction increased from $0.08 \mathrm{M}$ / $\mathrm{min} / \mathrm{g}$ catalyst to $0.16 \mathrm{M} / \mathrm{min} / \mathrm{g}$ catalyst as the speed of agitation increased from 100 to $200 \mathrm{rpm}$. Besides, there was an insignificant decline in the percentage conversion at $250 \mathrm{rpm}$. This can be elucidated to higher stirring speed that may trigger the enzyme particle to propel outside the liquid reaction mixture resulting the enzyme particles to project towards the wall of the reactor. Moreover, agitation speed beyond $200 \mathrm{rpm}$ may also lead to shearing of immobilized enzyme and undergo decay of enzyme leading to loss of enzyme activity. Hence, the speed of agitation of $200 \mathrm{rpm}$ has been investigated as optimal and well-chosen for further studies.

\subsection{Enzyme reusability}

To make the method economically applicable, the reusability of the immobilized lipase was checked by using the recovered enzyme for successive cycles under optimized reaction condition. After completion of each cycle, the crude reaction mixture was strained and filtered with the help of Whatman filter paper and washed several instants with acetone in order to eliminate the remains of product or reactants and preserved overnight in desiccators for drying at room temperature before reuse. The recycled enzyme was reused to determine the reusability. As seen in Fig. 6 the immobilized lipase retained proportionate activity up to 6 cycles for cetyl caprate synthesis. The relative decline in conversion beyond 6 cycles can be attributed due to deactivation of the enzyme by the use of cetyl alcohol. Moreover, loss of enzyme during the workup process may reduce the subsequent conversion rate [33,34].

\section{Kinetic modeling and mechanistic study}

The influence of concentration of substrate towards the rate of reaction between capric acid and cetyl alcohol was evaluated in the presence of immobilized enzyme lipase in SFS. To compute initial rates, trials were performed by varying the cetyl alcohol concentration, and the total volume of the reaction was kept constant at $15 \mathrm{~cm}^{3}$ in solvent free condition. The initial reaction rate was calculated and plotted from the records of reaction duration and initial rates with respect to acid concentration were plotted [35]. The Lineweaver-Burk plot of reciprocal of rate against 


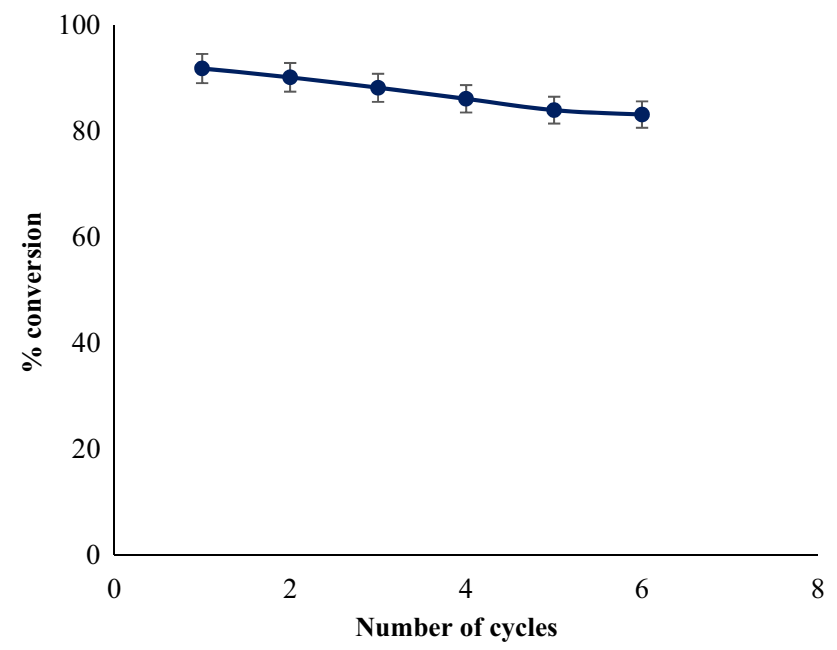

Fig. 6 Reusability study of lipase for cetyl caprate synthesis. Reaction conditions: time- $80 \mathrm{~min}$, temperature- $55{ }^{\circ} \mathrm{C}$, enzyme dose$3 \% \mathrm{w} / \mathrm{w}$, capric acid:cetyl alcohol ratio-1:3 and agitation speed$200 \mathrm{rpm}$

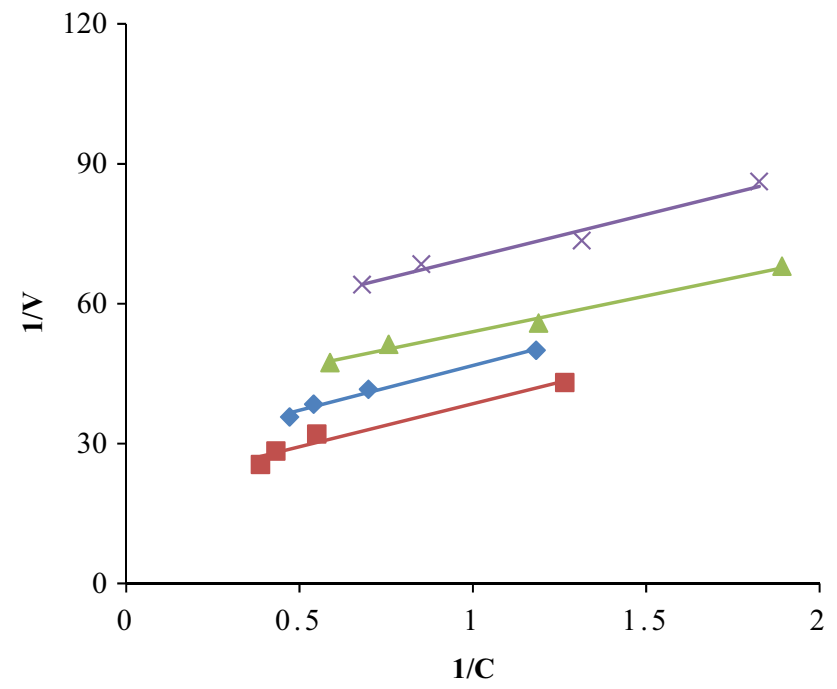

Fig. 7 Lineweaver-Burk plot

reciprocal of acid concentration is depicted in Fig. 7. As seen in Fig. 7 the initial rate increases at low concentration of alcohol and contrary is the situation when the concentration of cetyl alcohol is higher, which implicits that cetyl alcohol acts as an inhibitor. It can be considered that the deactivation of enzyme lipase can be caused by cetyl alcohol.

With the intention to assess the kinetics of the lipase catalyzed esterification reaction, various bi substrate models, such as random bi-bi, ping pong bi-bi, ordered bi-bi were selected. The calculations were examined with non-linear regression by using MS excel 2010 for the above mentioned models. It is seen that the sum of square (SSE) was minimum in the case of ping-pong bi-bi model with inhibition by cetyl alcohol and the SSE value was higher for the other two models. On the contrary, ordered bi-bi and random bi-bi models does not show good fit and some unambiguous kinetic parameters showed impractical and insignificant values $[36,37]$. The estimated kinetic parameters determined by ping pong bi-bi model were $V_{\text {max }}=21.89 \mathrm{M} / \mathrm{min} / \mathrm{g}$ catalyst, $K_{A}=1.19 \times 10^{-2} \mathrm{M}$, $K_{B}=8.45 \mathrm{M}, K_{i A}=2.02 \times 10^{-2} \mathrm{M}, K_{i B}=3.55 \times 10^{-4} \mathrm{M}$ and $S S E=4.31 \times 10^{-5}$. In view of this, it can be inferred that the reaction obeys and follows ping-pong bi-bi mechanism with inhibition by cetyl alcohol. Considering the association to the traditional mechanism of lipase catalyzed esterification, it can be postulated that capric acid (A) binds to the enzyme lipase (E) to constitute Enzyme-Acid complex (EA). The complex release water as the initial by product (P) and reformed enzyme (E) before second substrate, cetyl alcohol (B) attach with an enzyme (F) to present another complex (FB). The unstable complex further isomerizes to yield product cetyl caprate ester $(\mathrm{Q})$ and free enzyme (E). The rate equation for ping pong bi-bi model is given below as follow:

$E=A_{\Leftrightarrow}^{K_{A}} E \cdot A_{\Leftrightarrow}^{K_{E A}} F \cdot P_{\Leftrightarrow}^{K_{p}} F \cdot B_{\Leftrightarrow}^{K_{B}} F \cdot B_{\Leftrightarrow}^{K_{F B}} E \cdot Q_{\Theta}^{K_{Q}} E+Q$

The equation of the initial rate is represented below as follows:

$v_{0}=\frac{v_{\max }[A][B]}{[A][B]+K_{B}[A]+\left(1+[A] / K_{i A}\right)+K_{A}[B]\left(1+[B] / K_{i B}\right)}$

$v_{0}$ is the reaction rate, $V_{\text {max }}$ is the maximum rate of reaction, $[A]$ is the initial concentration of cetyl alcohol, $[B]$ is the initial concentration of capric acid, $K A$ is Michaelis constant for cetyl alcohol, KB is Michaelis constant for capric acid, KiA, inhibition constant for cetyl alcohol, and KiB is the inhibition constant for capric acid.

The assessment between experimental and predicted rates are plotted and compared in Fig. $8 \mathrm{a}$. It can be seen from Fig. $8 \mathrm{~b}$ that the initial rate of reaction is increased together with the corresponding rise in acid concentration and a higher initial rate has been obtained at approximately $0.07 \mathrm{M} / \mathrm{min} / \mathrm{g}$ of catalyst. It is observed from Fig. 8 a, $b$ that ping pong bi-bi model shows excellent match with experimental rates, thus demonstrating the plausibility of the model. The correlation table of kinetic parameter 

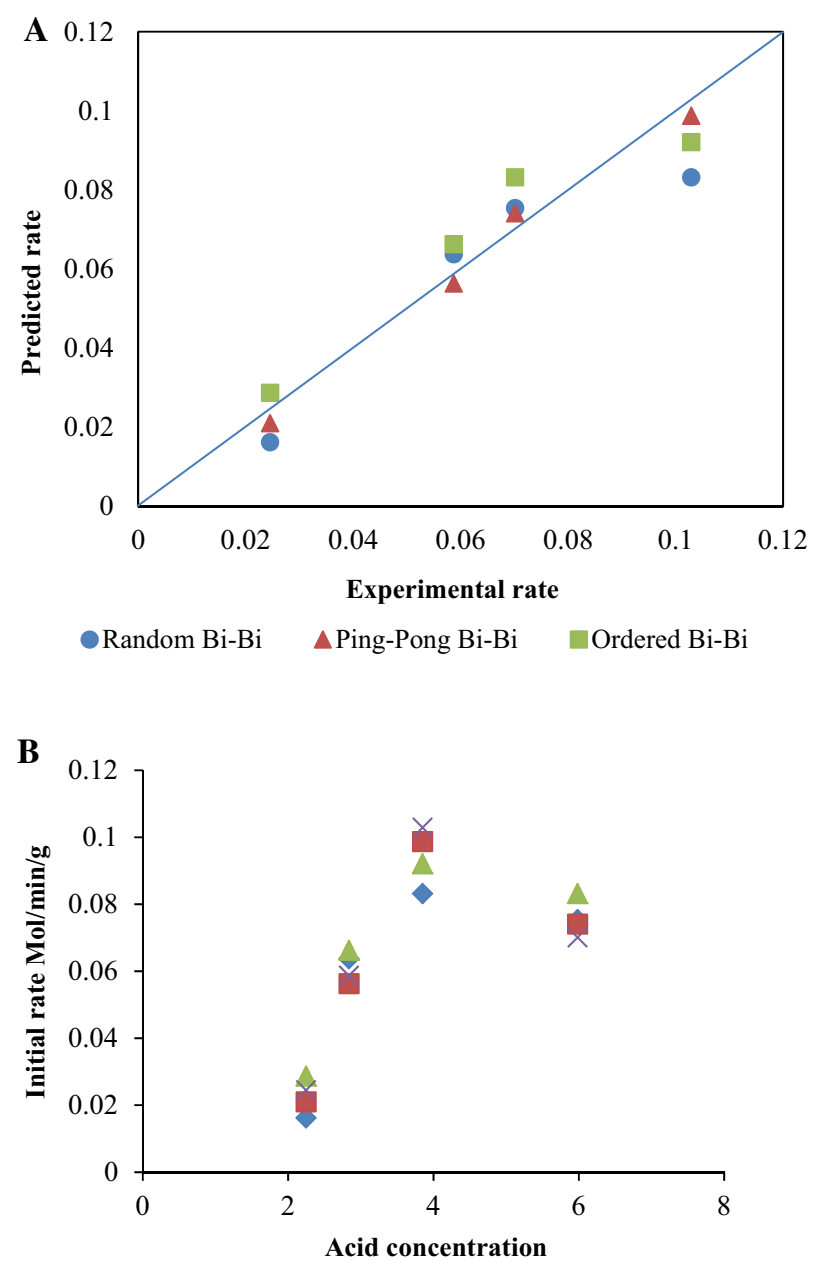

$\diamond$ Random Bi-Bi $\quad$ Ping pong bi bi $\triangle$ ordered bi bi $\quad \times$ Experimental

Fig. 8 Parity plot of predicted rate versus experimental rate (a) and comparison of initial rate versus acid concentration in case of all three models with experimental results (b)

Table 1 Comparison table of kinetic parameter values for the cetyl caprate synthesis

\begin{tabular}{llll}
\hline Parameters & \multicolumn{2}{l}{ Kinetic model } & \\
\cline { 2 - 4 } & Random bi-bi & Ping Pong bi-bi & Ordered bi-bi \\
\hline Vm (M/min/g) & 1.70427 & 21.886 & 12.3211 \\
KB (M) & $7.0197 \times 10^{-1}$ & 8.45123 & $7.306 \times 10^{-1}$ \\
KA(M) & 1.198948 & $1.194 \times 10^{-2}$ & 1.1032 \\
KiA (M) & 14.8832 & $2.02 \times 10^{-2}$ & $1.5208 \times 10^{-1}$ \\
KiB (M) & - & $3.55 \times 10^{-4}$ & - \\
Ki (M) & - & - & $1.805 \times 10^{-3}$ \\
SSE & $5.18 \times 10^{-4}$ & $4.31 \times 10^{-5}$ & $1.14 \times 10^{-4}$ \\
\hline
\end{tabular}

statistics for the synthesis of cetyl caprate is illustrated in Table 1.

\section{Thermodynamic viewpoint}

The thermodynamic feasibility study of kinetic data was carried out by using Erying equation. By integrating the basic thermodynamic equation and substituting the relevant values, additional values of $\Delta \mathrm{H}, \Delta \mathrm{S}$, and $\Delta \mathrm{G}$ of the reaction were derived. Throughout the reaction, enzyme lipase can deflate the free energy, which is essential to discharge the product along with a combination of reacting groups [38]. Thus enzymes even out the transition state; pace up reaction rate and the energy obstacle to conquer is marked down. The minimal activation energy was noted for a refined protocol that suggested (a) improved catalytic performance (b) decreased energy pre-conditions (c) substantial rate of reaction for the given system in comparison to various other catalyzed reaction [39-41]. Thermodynamic aspect can contribute the notable evidence with respect to reaction practicability of various biocatalysed approach [42]. The enthalpy change $(\Delta \mathrm{H})$ indicates unconstrained re-order and randomness of lipase catalyzed system; the minimal $\Delta \mathrm{H}$ value was found $43.31 \mathrm{~kJ} /$ mol which can be attributed to facile transition state formation and the enthalpy change obtained is positive for various temperatures. Similar values for enthalpy change can be seen for the synthesis of cetyl oleate catalyzed by lipase immobilized on glutaraldehyde-activated rice husk particles, indicating that the reaction is endothermic in nature [39]. As per the second law of thermodynamics, the entropy of activation $(\Delta S)$ designates the analysis of localized disorderness of the reaction system. With the progress of the reaction, the reactants are utilized, leading to the formation of enzyme-substrate complexes (ES) and deprivation of entropy accompany with the liberation of both translational and rotational energies. Consequently, the entropy is explicit as a negative value $(-0.25 \mathrm{~kJ} / \mathrm{mol} \mathrm{K})$, which suggests favorable and impulsive complex formation [43]. The practicality and simplicity of reaction are appropriately defined in terms of free energy change of activation $(\Delta G)$. The feasibility of reaction is more with the lower free energy change of reaction [37]. The Gibb's free energy change $(\Delta \mathrm{G})$ was determined as $126.06 \mathrm{~kJ} /$ mol, which revealed no alteration at different operating temperatures. The rate data at different temperatures and energy of activation are shown in Table 2. 
Table 2 Energy of activation and thermodynamic parameter at different temperature

\begin{tabular}{|c|c|c|c|c|}
\hline \multirow[t]{2}{*}{ Parameter } & \multicolumn{4}{|c|}{ Temperature (K) } \\
\hline & 313 & 318 & 323 & 328 \\
\hline $\begin{array}{l}\text { Energy of activation, Ea (KJ/ } \\
\text { mol) }\end{array}$ & - & - & 45.99 & - \\
\hline Enthalpy change $(\Delta \mathrm{H}) \mathrm{KJ} / \mathrm{mol}$ & 43.39 & 43.34 & 43.30 & 43.27 \\
\hline Entropy change $(\Delta \mathrm{S}) \mathrm{KJ} / \mathrm{mol} \mathrm{K}$ & -0.255 & -0.256 & -0.256 & -0.256 \\
\hline $\begin{array}{l}\text { Free energy change }(\Delta \mathrm{G}) \mathrm{KJ} / \\
\mathrm{mol}\end{array}$ & 123.50 & 124.78 & 126.06 & 127.34 \\
\hline
\end{tabular}

\section{Conclusion}

The present study validates that the synthesis of cetyl caprate, a cosmetic value ester using Fermase $\mathrm{CALB}^{\mathrm{TM}} 10000$, a commercial immobilized Candida antarctica lipase, has been accomplished using cetyl alcohol and capric acid in short duration time. The influence of different operating parameters has been studied under solvent free condition, and the highest percentage conversion of cetyl caprate ester (95\%) was achieved under optimal conditions of $3 \% \mathrm{w} / \mathrm{w}$ of enzyme dose, $60^{\circ} \mathrm{C}$ temperature for $80 \mathrm{~min}$ at a stirring speed of $200 \mathrm{rpm}$ with 1:3 molar ratio. The immobilized lipase was reused up to 5-6 cycles reserving its respective actual activity. The energy of activation was found to be $45.99 \mathrm{~kJ} / \mathrm{mol}$. The thermodynamic parameters were estimated at various temperatures. Enthalpy change $(\Delta \mathrm{H})$ and Gibbs free energy change $(\Delta \mathrm{G})$ were enumerated as $43.30 \mathrm{~kJ} / \mathrm{mol}$ and $126.06 \mathrm{~kJ} / \mathrm{mol}$ respectively. The entropy change $(\Delta \mathrm{S})$ was found as $-0.25 \mathrm{~kJ} /$ mol $k$. The enzymatic synthesis of cosmetic ester is recognized as favorable greener and environmentally friendly approach and cosmetic ester can be used as a cosmetic ingredient in various commercial cosmetic formulations.

\section{Compliance with ethical standards}

Conflict of interest The authors declare that they have no conflict of interest.

\section{References}

1. Kuo CH, Chen HH, Chen JH, Liu YC, Shieh CJ (2012) High yield of wax ester synthesized from cetyl alcohol and octanoic acid by lipozyme RMIM and Novozym 435. Int J Mol Sci 13:11694-11704

2. leda N, Mantri K, Miyata Y, Ozaki A, Komura K, Sugi Y (2008) Esterification of long-chain acids and alcohols catalyzed by ferric chloride hexahydrate esterification of long-chain acids and alcohols catalyzed by ferric chloride. Ind Crops Prod 47:8631-8638

3. Deng L, Wang X, Nie K, Wang F, Liu J, Wang P, Tan T (2011) Synthesis of wax esters by lipase-catalyzed esterification with immobilised lipase from Candida sp. 99-125. Chin J Chem Eng 19:978-982

4. Khan NR, Jadhav SV, Rathod VK (2015) Lipase catalysed synthesis of cetyl oleate using ultrasound: optimisation and kinetic studies. Ultrason Sonochem 27:522-529

5. Rocha JMS, Gil MH, Garcia FAP (1999) Optimisation of the enzymatic synthesis of n-octyl oleate with immobilised lipase in the absence of solvents. J Chem Technol Biotechnol 74:607-612

6. Bidjou-Haiour C, Klai N (2013) Lipase catalyzed synthesis of fatty acid xylose esters and their surfactant properties. Asian J Chem 25:4347-4350

7. Serrano-Arnaldos M, Máximo-Martín MF, Montiel-Morte MC, Ortega-Requena S, Gómez-Gómez E, Bastida-Rodríguez J (2016) Solvent-free enzymatic production of high quality cetyl esters. Bioprocess Biosyst, Eng, p 39

8. Chen H-C, Twu Y-K, Chang CJ, Liu Y-C, Shieh C-J (2010) Optimized synthesis of lipase-catalyzed octyl caffeate by Novozym 435. Ind Crops Prod 32:522-526

9. Adnani A, Basri M, Malek EA, Salleh AB, Abdul Rahman MB, Chaibakhsh N, Rahman RNZRA (2010) Optimization of lipasecatalyzed synthesis of xylitol ester by Taguchi robust design method. Ind Crops Prod 31:350-356

10. Khan NR, Rathod VK (2015) Enzyme catalyzed synthesis of cosmetic esters and its intensification: a review. Process Biochem 50:1793-1806

11. Garcia T, Coteron A, Martinez M, Aracil J (2000) Kinetic model for the esterification of oleic acid and cetyl alcohol using an immobilized lipase as catalyst. Chem Eng Sci 55:1411-1423

12. Mathpati AC, Badgujar KC, Bhanage BM (2016) Kinetic modeling and docking study of immobilized lipase catalyzed synthesis of furfuryl acetate. Enzyme Microb Technol 84:1-10

13. Singh P, Saxena DK, Naik SN (2014) Synthesis of food flavors by enzymatic esterification process. Int J Sci Res 3:2113-2116

14. Kwon DY, Hong YJ, Yoon SH (2000) Enantiomeric synthesis of (S)2-methylbutanoic acid methyl ester, apple flavor, using lipases in organic solvent. J Agric Food Chem 48:524-530

15. Lerin LA, Feiten MC, Richetti A, Toniazzo G, Treichel H, Mazutti MA, Vladimir Oliveira J, Oestreicher EG, De Oliveira D (2011) Enzymatic synthesis of ascorbyl palmitate in ultrasound-assisted system: process optimization and kinetic evaluation. Ultrason Sonochem 18:988-996

16. Mohamad N, Huyop F, Aboul-Enein HY, Mahat NA, Wahab RA (2015) Response surface methodological approach for optimizing production of geranyl propionate catalysed by carbon nanotubes nanobioconjugates. Biotechnol Biotechnol Equip 29:732-739

17. Badgujar KC, Bhanage BM (2016) The green metric evaluation and synthesis of diesel-blend compounds from biomass derived levulinic acid in supercritical carbon dioxide. Biomass Bioenergy 84:12-21

18. Bansode SR, Rathod VK (2014) Ultrasound assisted lipase catalysed synthesis of isoamyl butyrate. Process Biochem 49:1297-1303

19. Gawas SD, Jadhav SV, Rathod VK (2016) Solvent free lipase catalysed synthesis of ethyl laurate: optimization and kinetic studies. Appl Biochem Biotechnol 180:1428-1445

20. Al ET (2012) Evaluation of activation energy and thermodynamic properties of enzyme-catalysed transesterification reactions. ACES 2:150-154

21. Rani KNP, Neeharika TSVR, Kumar TP, Satyavathi B, Sailu C, Prasad RBN (2015) Kinetics of enzymatic esterification of oleic acid and decanol for wax ester and evaluation of its physico-chemical properties. J Taiwan Inst Chem Eng 55:12-16

22. Jaiswal KS, Rathod VK (2018) Acoustic cavitation promoted lipase catalysed synthesis of isobutylpropionate in solvent free 
system: optimization and kinetic studies. Ultrason Sonochem 40:727-735

23. Kuperkar VV, Lade VG, Prakash A, Rathod VK (2014) Synthesis of isobutyl propionate using immobilized lipase in a solvent free system: optimization and kinetic studies. J Mol Catal B Enzym 99:143-149

24. Pawar SV, Yadav GD (2015) Kinetics and mechanism of regioselective monoacetylation of 3-aryloxy-1,2-propandiols using immobilized Candida antarctica lipase. J Ind Eng Chem 31:335-342

25. Foresti ML, Ferreira ML (2005) Solvent-free ethyl oleate synthesis mediated by lipase from Candida antarctica B adsorbed on polypropylene powder. Catal Today 107-108:23-30

26. Abdulmalek E, Hamidon NF, Abdul Rahman MB (2016) Optimization and characterization of lipase catalysed synthesis of xylose caproate ester in organic solvents. J Mol Catal B Enzym 132:1-4

27. Alves MD, Cren ÉC, Mendes AA (2016) Kinetic, thermodynamic, optimization and reusability studies for the enzymatic synthesis of a saturated wax ester. J Mol Catal B Enzym 133:S377-S387

28. Yadav GD, Trivedi AH (2003) Kinetic modeling of immobilizedlipase catalyzed transesterification of $n$-octanol with vinyl acetate in non-aqueous media. Enzyme Microb Technol 32:783-789

29. Manohar B, Divakar S (2005) An artificial neural network analysis of porcine pancreas lipase catalysed esterification of anthranilic acid with methanol. Process Biochem 40:3372-3376

30. Ghamgui H, Karra-cha^ M, Bezzine S, Miled N, Gargouri Y (2005) Production of isoamyl acetate with immobilized Staphylococcus simulans lipase in a solvent-free system. Enzyme Microb Technol 38:788-794

31. Claon PA, Akoh CC (1994) Effect of reaction parameters on SP435 lipase-catalyzed synthesis of citronellyl acetate in organic solvent. Enzyme Microb Technol 16:835-838

32. Foresti ML, Errazu A, Ferreira ML (2005) Effect of several reaction parameters in the solvent-free ethyl oleate synthesis using Candida rugosa lipase immobilised on polypropylene. Biochem Eng J 25:69-77

33. Choudhury HA, Malani RS, Moholkar VS (2013) Acid catalyzed biodiesel synthesis from Jatropha oil: mechanistic aspects of ultrasonic intensification. Chem Eng J 231:262-272
34. Yu D, Tian L, Wu H, Wang S, Wang Y, Ma D, Fang X (2010) Ultrasonic irradiation with vibration for biodiesel production from soybean oil by Novozym 435. Process Biochem 45:519-525

35. Badgujar KC, Bhanage BM (2014) Application of lipase immobilized on the biocompatible ternary blend polymer matrix for synthesis of citronellyl acetate in non-aqueous media: kinetic modelling study. Enzyme Microb Technol 57:16-25

36. Bezbradica D, Mijin D, Siler-Marinkovic S, Knezevic Z (2006) The Candida rugosa lipase catalyzed synthesis of amyl isobutyrate in organic solvent and solvent-free system: a kinetic study. J Mol Catal B Enzym 38:11-16

37. Yadav GD, Thorat PA (2012) Microwave assisted lipase catalyzed synthesis of isoamyl myristate in solvent-free system. J Mol Catal B Enzym 83:16-22

38. Lima LCD, Peres DGC, Mendes AA (2018) Kinetic and thermodynamic studies on the enzymatic synthesis of wax ester catalyzed by lipase immobilized on glutaraldehyde-activated rice husk particles. Bioprocess Biosyst Eng 41:991-1002

39. Jadhav SH, Gogate PR (2014) Intensification in the activity of lipase enzyme using ultrasonic irradiation and stability studies. Ind Eng Chem Res 53:1377-1385

40. Badgujar KC, Bhanage BM (2015) The combine use of ultrasound and lipase immobilized on co-polymer matrix for efficient biocatalytic application studies. J Mol Catal B Enzym 122:255-264

41. Sharma A, Dalai AK, Chaurasia SP (2015) Thermodynamic study of hydrolysis and esterification reactions with immobilized lipases. EIJST 4:128-136

42. Badgujar KC, Bhanage BM (2015) Thermo-chemical energy assessment for production of energy-rich fuel additive compounds by using levulinic acid and immobilized lipase. Fuel Process Technol 138:139-146

43. Badgujar KC, Bhanage BM (2016) Lipase immobilization on hyroxypropyl methyl cellulose support and its applications for chemo-selective synthesis of amino ester compounds. Process Biochem 51:1420-1433

Publisher's Note Springer Nature remains neutral with regard to jurisdictional claims in published maps and institutional affiliations. 